\title{
A novel GJA8 mutation in an Iranian family with progressive autosomal dominant congenital nuclear cataract
}

\author{
C E Willoughby, Sara Arab, R Gandhi, S Zeinali, Seddigheh Arab, D Luk, G Billingsley, \\ F L Munier, E Héon
}

J Med Genet 2003;40:124 (http://www.jmedgenet.com/cgi/content/full/40/11/124)

C ataract results from a loss in transparency of the crystalline lens. Worldwide, there are an estimated 20 million people blind (Snellen visual acuity of 3/60 or less) as a result of cataract. ${ }^{1}$ Despite effective surgical treatment, demand outstrips supply in both Western and developing countries, for many reasons, ${ }^{23}$ and other disease modifying strategies must be considered. A strong genetic predisposition to the development of congenital cataract and age related cataract has been well documented. ${ }^{45}$ Inherited cataract accounts for at least $50 \%$ of all congenital cataracts, ${ }^{6}$ and shows marked inter- and intrafamilial variation. ${ }^{7}$ Twin studies on age related cataracts in the United Kingdom estimate that two thirds of cortical cataract and at least half of nuclear cataracts can be explained by genetic factors. ${ }^{8}$,

Previous genetic studies of congenital cataracts identified connexin $50(C \times 50)$ as a cataract related gene. ${ }^{10-12}$ Here we report a novel heterozygous R23T mutation in the GJA8 gene (MIM\#600897) encoding connexin 50, in an Iranian family affected by a progressive autosomal dominant congenital

\section{Key points}

- The molecular characterisation of an Iranian family with an autosomal dominant progressive congenital nuclear cataract is described. Affected members were found to have a novel heterozygous missense mutation R23T in the GJA8 gene encoding connexin 50 ( $\mathrm{Cx} 50)$. This sequence change segregated with the disease phenotype in the family and was not found in 152 control individuals, including 52 ethnically matched controls.

- This non-conservative mutation replaces an evolutionary conserved basic polar charged amino acid by an uncharged polar amino acid at position 23 in the amino-terminus of $\mathrm{C} \times 50$. The R32T mutation may result in failure to form normal gap junctions (loss of function mutation) or alter the function of endogenous wild-type connexins (dominant negative mutation).

- In this family, there was a novel progressive phenotype, mimicking an early onset age related nuclear cataract. Three heterozygous missense Cx50 mutations (P88S, $\mathrm{E} 48 \mathrm{~K}$, and $(247 \mathrm{M})$ have previously been described in three geographically distinct families with zonular pulverulent or zonular nuclear congenital cataracts. The mutational screening of a population of patients with congenital cataracts $(n=37)$ and another with age related cataract $(n=44)$ failed to show any contribution of the four known Cx50 mutations. nuclear cataract. In addition, to determine the genetic contribution of connexin 50 mutations to the basis of congenital and age related cataracts for our mutation (R23T) and the other three published Cx50 mutations (P88S, E48K, and I247M) ${ }^{10-12}$, two additional patient populations were screened for those changes.

\section{METHODS}

Observing the principles of the Declaration of Helsinki, a four generation Iranian family with autosomal dominant congenital cataract was recruited for molecular analysis (fig 1A). Twenty seven family members (12 affected and 15 unaffected) participated and had a full ocular assessment to document the phenotype. The phenotype was characterised by autosomal dominant, bilateral, congenital nuclear cataracts that progressed to cause visual impairment by the second decade. No other systemic findings or ocular defects were present, including microcornea or microphthalmia. All participants required cataract surgery and intraocular lens implantation in the second and third decades because of dense nuclear (fetal/embryonal) cataract. There was no evidence of nystagmus, and reasonably good visual function was obtained postoperatively (range of Snellen visual acuity $6 / 9.5$ to 6/12). This suggests that visual deprivation was minimal in the critical period of visual development.

With informed consent, genomic DNA was extracted from peripheral blood leucocytes using standard protocols. The affected status (presence of cataracts) was determined before genetic analysis. A panel of cataract candidate loci was selected for preliminary haplotype analysis. Polymerase chain reaction (PCR) based genotyping of microsatellite markers was done on a Pharmacia automated sequencer. The marker order (centromeric to telomeric) and the intermarker distances (centiMorgans (cM)) were obtained from the Marshfield Genetic Database (www.marshfield.org/genetics/ maps). The position of genes in relation to markers was determined using the UCSC Human Genome Browser (http:// genome.ucsc.edu). Haplotype analysis of the genotypes from markers of a $9 \mathrm{cM}$ region on chromosome l (D1S26691.11cM - D1S514 - 8.60cM - D1S1595) suggested putative linkage (fig 1A). Linkage analysis using the MLINK program of the LINKAGE package v5.2 gave a maximum two point LOD score $\left(Z_{\text {Max }}\right)$ of 2.62 for marker DiS514 $(\theta=0.05)$ (table 1). This region contained a strong candidate, the GJA8 gene encoding connexin 50 ( $\mathrm{Cx} 50)$, as $\mathrm{Cx} 50$ mutations cause cataracts in humans and mice. ${ }^{10-12}{ }^{14}$ Connexin 50 consists of two exons, of which only one is coding (exon 2). The coding of $\mathrm{Cx} 50$ (GJA8) was sequenced using published protocols. $^{10}{ }^{1137}$ Primers were modified from those published earlier ${ }^{10}$ or designed from the genomic sequence (http://www.ncbi.nlm.nih.gov/GenBank/for genomic contig NT_034400.2; gi:27478327), to amplify two overlapping 


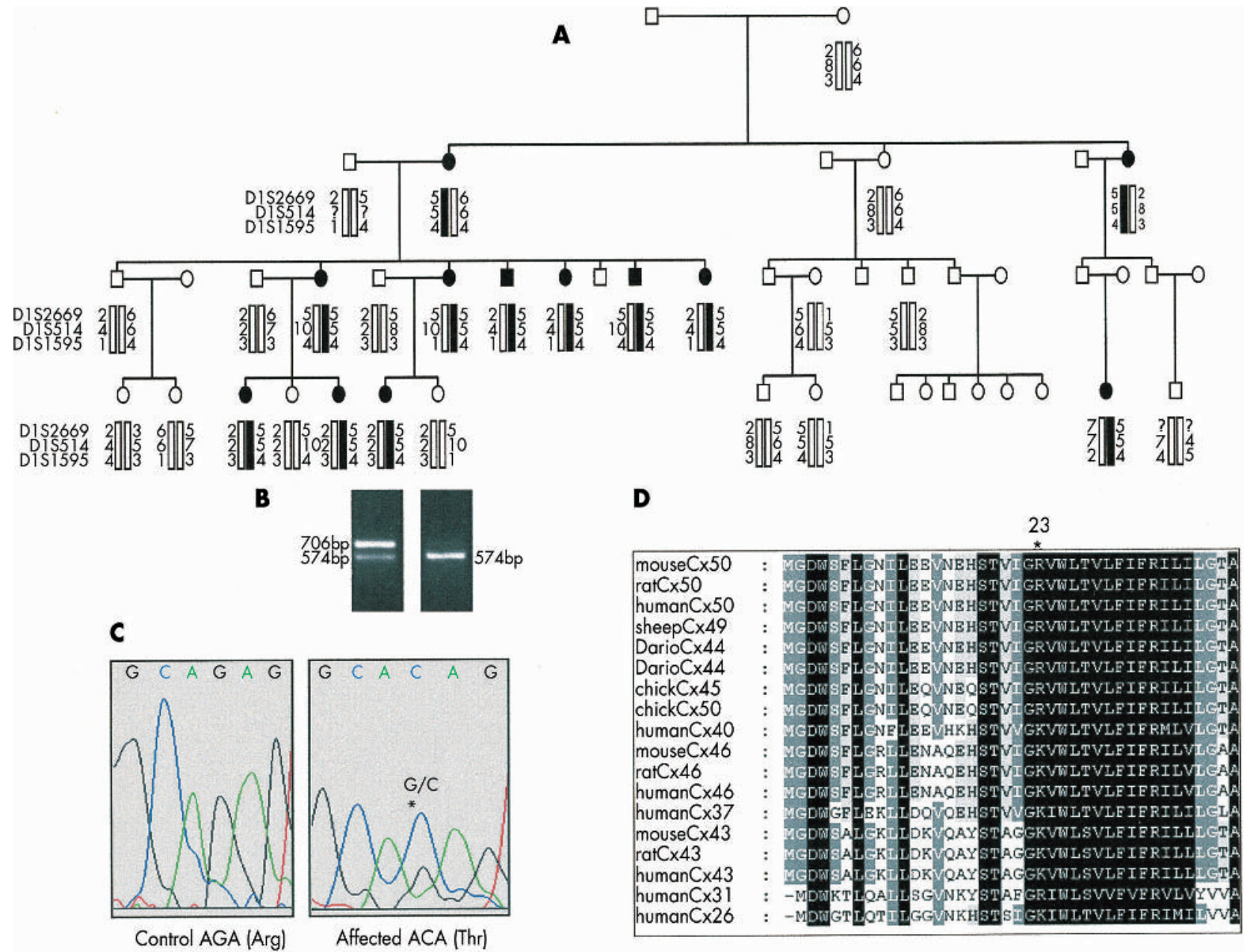

Figure 1 (A) Pedigree and haplotype analysis of family showing segregation of three microsatellite markers on chromosome 1, listed in descending order from the centromere. Black symbols indicate clinically affected individuals; white symbols represent unaffected relatives. The disease haplotype is indicated as a black bar with alleles D1S2669 (5), D1S514 (5), and D1S1595 (4). (B) Conformation by restriction digest of R23T mutation segregation in the family, which results in the loss of a cut site for the enzyme Hinfl, producing an undigested fragment of 706 base pairs (bp) compared with the control fragments of $574 \mathrm{bp}$ and $132 \mathrm{bp}$ (band not shown) and a common $27 \mathrm{bp}$ fragment (not shown). (C) Sequence chromatograms showing the mutation detected in family with a heterozygous $68 \mathrm{G} \rightarrow C$ transition that converts an arginine residue (AGA) to threonine (ACA). (D) Sequence alignment (Clustal X38; ftp://ftp-igbmc.u-strasbg.fr/pub/ClustalX/) of $\mathrm{Cx50}$ with other connexin proteins. Identical residues are highlighted with a dark background. The asterisk indicates the position of the R23T mutation where an arginine (R) or lysine (K) (basic polar group) is highly conserved throughout all connexins.

amplicons of exon 2 of Cx50: amplicon 1 (847 base pairs (bp)) F5'-cactacttcctgtacgggttc-3' and R5'-ctcttgccetacgtaagcttgg-3'; amplicon 2 (733 bp) F5'-cccgcgttagcaaaaacagat-3' and R5'-cacagaggccacagacaacat-3'. Bidirectional sequencing detected the transition $68 \mathrm{G} \rightarrow \mathrm{C}$ resulting in the substitution of an arginine residue (A $\underline{G A}$ ) to threonine (ACA) in codon 23 (R23T) (fig lC).

\section{RESULTS}

The presence of the mutation was confirmed by the loss of a restriction site for the enzyme HinfI (fig 1B; table 2). Wild type control PCR products were digested into fragments of 574, 132, and $27 \mathrm{bp}$, while the presence of the R23T mutation resulted in an undigested fragment of $706 \mathrm{bp}$ as well as a common $27 \mathrm{bp}$ fragment. The sequence alteration segregated with the phenotype of all family members. Analysis of 100 mixed ethnicity control individuals and 52 ethnically matched controls failed to detect this sequence variation, suggesting that the $68 \mathrm{G} \rightarrow \mathrm{C}$ change was not a polymorphic variant. To test the contribution that our mutation (R23T) and the three other published Cx50 mutations (P88S, E48K, and $\mathrm{I} 247 \mathrm{M})^{10-12}$ make to the genetic basis of cataract, we

Table 1 Two point $z$ values for cataract phenotype and chromosome lq markers

\begin{tabular}{|c|c|c|c|c|c|c|c|c|}
\hline \multirow[b]{2}{*}{ Marker } & \multicolumn{6}{|c|}{ LOD score at recombination fraction } & \multirow[b]{2}{*}{$z \max$} & \multirow[b]{2}{*}{$\theta \max$} \\
\hline & 0 & 0.05 & 0.10 & 0.20 & 0.30 & 0.40 & & \\
\hline D1S2669 & -1.22 & 1.24 & 1.29 & 1.07 & 0.67 & 0.23 & 1.29 & 0.10 \\
\hline D1S514 & 0.26 & 2.62 & 2.55 & 2.07 & 1.39 & 0.62 & 2.62 & 0.05 \\
\hline D1S1595 & -7.99 & -0.97 & -0.065 & -0.31 & -0.12 & -0.02 & -0.02 & 0.40 \\
\hline
\end{tabular}


Table 2 Polymerase chain reaction primers and restriction digest fragment sizes used to screen the congenital and age related cataract populations for the four known Cx50 mutations

\begin{tabular}{lllll}
\hline Mutation & Restriction site & Primers (sense/antisense) & Wild type (bp) & Mutant (bp) \\
\hline R23T & Loss of HINf1 & $\begin{array}{l}\text { F5'-cccgcgttagcaaaaacagat-3' and } \\
\text { R5'-cacagaggccacagacaacat-3' }\end{array}$ & $574,132,27$ & 706,27 \\
P88S & Creates Mnl1 & $\begin{array}{l}\text { F5'-tctgggtgctgcagatcatc-3' } \\
\text { R5'-ccatgcggacgtagtgcac-3' }\end{array}$ & 81 & 50,31 \\
E48K & Loss of Fokl & $\begin{array}{l}\text { F5'-cccgcgttagcaaaaacagat-3' } \\
\text { R5'-ccatgcggacgtagtgcac-3' }\end{array}$ & $193,172,33$ & 193,205 \\
I247M & Loss of HINf1 & $\begin{array}{l}\text { F5'-cactacttcctgtacgggttc-3' } \\
\text { R5'-ctcttgcctacgtaagcttgg-3' }\end{array}$ & 610,237 & 847 \\
\hline
\end{tabular}

screened two groups for these mutations by restriction endonuclease analysis (table 2). The first group consisted of 37 Swiss patients with congenital and juvenile cataracts, and the second of 44 Swiss patients with age related nuclear sclerotic cataracts. The four known Cx50 mutations were not detected in this study population.

\section{DISCUSSION}

Connexins are a large family of transmembrane proteins that form gap junctions. ${ }^{15}$ All connexins have four transmembrane domains and two extracellular loops with cytoplasmic $\mathrm{N}$ and $\mathrm{C}$ termini (fig 2). A single gap junction is formed from two connexon hemichannels, from adjacent cells, which are constructed from hexameric oligomerisation of protein subunits or connexins. ${ }^{15}{ }^{17}$ The $68 \mathrm{G} \rightarrow \mathrm{C}$ change results in an arginine $(\mathrm{R})$ to threonine $(\mathrm{T})$ amino acid substitution within the cytoplasmic $\mathrm{N}$ terminus region at the membranecytoplasm boundary of the first transmembrane domain (Ml: amino acids 24-45; fig 2). This non-conservative mutation (R23T) replaces a basic polar charged amino acid by an uncharged polar amino acid at position 23 in the amino terminus. Positively charged amino acid residues in the hydrophilic cytoplasmic domains of membrane proteins are important factors in the membrane insertion and orientation of hydrophobic transmembrane elements. ${ }^{18}$ An arginine (R) or lysine $(\mathrm{K})$ residue, both basic polar charged amino acids, are evolutionarily conserved residues across species for connexin 50 and other $\mathrm{Cx}$ molecules at that position (fig 1D). Substitutions in the amino acid residues of the $\mathrm{N}$ terminus may interfere with the conformation and flexibility of the amino terminus, and also with voltage gating. ${ }^{19}{ }^{20}$ In addition, the mutation may have a dominant negative effect owing to a direct interaction of the intact and defective connexins at the plasma membrane level. ${ }^{21}$ Mutations in the $\mathrm{N}$ terminus of other connexins have been documented in

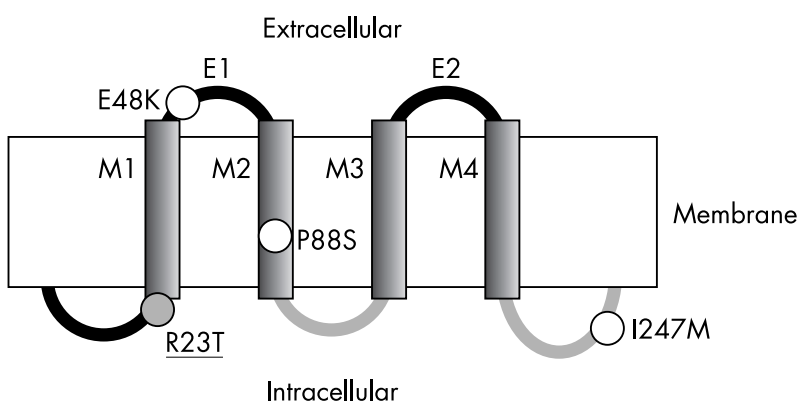

Figure 2 Schematic diagram of the predicted $\mathrm{C} \times 50$ polypeptide and location of known mutations. M1-M4 transmembrane domains 1-4; El and E2, extracellular domains 1 and 2, respectively (HMM Top Prediction of Transmembrane Helices and Protein Topology server[16] (http://www.enzim.hu/hmmtop/).
Charcot-Marie-Tooth peripheral neuropathy $(\mathrm{C} \times 32),{ }^{22}$ autosomal recessive (DFNB1) and dominant (DFNA3) human deafness (Cx26) (http://www.crg.es/deafness/intro.htm), erythrokeratoderma variabilis $(\mathrm{Cx} 31)$, Clouston syndrome (Cx30), and keratitis-ichthyosis-deafness (KID) syndrome $(\mathrm{Cx} 26){ }^{23-25}$

Three previously published heterozygous missense Cx50 mutations (P88S, E48K, and I247M) have been described causing autosomal dominant congenital cataracts with either a zonular or zonular nuclear pulverulent cataract (CZPl; MIM\#116200). ${ }^{10-12}$ The P88S mutation is located in the second transmembrane domain (M2), the E48K in the first extracellular domain (E1), and the I247M in the cytoplasmic $\mathrm{C}$ terminus (fig 2). These mutations arose in three distinct ethnic populations-British, Pakistani, and Russian. ${ }^{10-12}$ Cataract progression was not reported in the P88S mutation but cataract was present at birth or developed in infancy, and all affected individuals had surgery at an unspecified time. ${ }^{10}$ The $\mathrm{E} 48 \mathrm{~K}$ mutation resulted in a non-progressive cataract that was present at birth or in early infancy ${ }^{11}$ and the I247M associated cataract began at three years of age in one individual with progression, but did not require cataract surgery; the level of visual impairment was not reported. ${ }^{12}$ The novel R23T mutation described here, unlike the previous Cx50 mutations, caused a progressive nuclear cataract that was present at birth and resulted in significant visual impairment in the second and third decades requiring cataract extraction.

Three connexins are expressed in the lens: connexin 43 (Cx43), connexin 46 (Cx46), and Cx50. ${ }^{26-28} \mathrm{Cx} 43$ is expressed mainly in the lens epithelial cells, while Cx46 and Cx50 are expressed in lens fibre cells. ${ }^{26-28}$ The lens is an avascular structure and lens fibres lose all intracellular organelles during development. The lens has developed an extensive cell-cell communication system using connexins to maintain its transparency. ${ }^{29}{ }^{30}$ Gap junction intercellular communication is an essential part of this system, which facilitates the exchange of ions, metabolites, signalling molecules, and other molecules with a molecular weight up to $1 \mathrm{kDa} .{ }^{17} 29$

Defects in Cx50 and Cx46 cause human and murine cataracts, but the specific roles of these two connexins in the lens are not fully understood. ${ }^{10-13}{ }^{30-36}$ Both Cx50 and Cx46 localise to the same gap junction plaque in the plasma membrane of lens fibre cells, and the size of these plaques in cortical fibres is dependent on the presence of Cx50. ${ }^{33}{ }^{36} \mathrm{Cx} 50$ knockout mice develop microphthalmia with small lenses and nuclear cataracts, indicating a role for $\mathrm{Cx} 50$ in lens and eye growth, as well as in the differentiation of lens fibres. ${ }^{33}{ }^{34}$ A naturally occurring Cx50 autosomal semidominant mutation (G22R) results in cataracts in the lens opacity 10 (Lop 10) mouse. ${ }^{137}$ This amino acid substitution, which is neighbour to our mutant residue (R23T), results failure to form normal gap junctions (loss-of-function mutation) and alters the function of endogenous wild type Cx46 (dominant negative 
mutation). Heterozygous mice, which are homologous to our family, have a variable expression of cataracts, ranging from no lens opacity to snowflake opacities (pulverulent) and to full expression with dense fetal nuclear opacities. ${ }^{13}{ }^{37} \mathrm{~A}$ second dominant mouse cataract mutant, No2, is caused by a different point mutation in $\mathrm{Cx} 50$, resulting in the substitution of aspartic acid with alanine at codon 47 (D47A). ${ }^{32}$ No histological or biochemical data were reported for the No2 mutant, but in vitro studies in Xenopus oocytes suggested the D47A mutation acts as a loss-of-function mutation..$^{31}$

What is clear from these human and murine studies is that different mutations in Cx50 can lead to distinctive cataract morphology. Evidence from the Loplo mutant suggests further complexity to cataractogenesis, with mutant Cx50 interacting with Cx46 and potentially with other lens proteins or intercellular communications. ${ }^{13}$ Whether or not these other cataract genes can act as modifiers of $\mathrm{Cx} 50$ has not been explored.

\section{Conclusions}

A novel heterozygous R23T mutation in the GJA8 gene encoding connexin 50 was identified in an Iranian family, causing a progressive autosomal dominant congenital nuclear cataract. Although this mutation is not common it further expands the genetic and phenotypic heterogeneity of cataract. The human connexin mutations identified to date do not appear to be a common cause of congenital or late onset cataract but they highlight the complexity of the clinical changes associated with connexin changes.

\section{ACKNOWLEDGEMENTS}

This work was supported by the Canadian Institutes of Health Research No CIHR94282 (EH), the Canadian Genetic Diseases Network (DL, EH), the Swiss National Science Foundation No 32065250 (FLM), and the BUPA Foundation, Royal College of Ophthalmologists and the Research Training Centre, The Hospital for Sick Children, Toronto (CEW).

\section{Authors' affiliations}

R Gandhi, G Billingsley, D Luk, Vision Science Research Program, Toronto Western Hospital, Toronto, Canada

C E Willoughby*, E Heon, Department of Opthalmology, The Hospital for Sick Children, University of Toronto, Toronto, Canada

Sara Arab*, Department of Cardiology, Heart and Stroke, Richard Lewar Centre of Excellence, Toronto General Hospital, University of Toronto

S Zeinali, Seddigheh Arab, Pasteur Institute, Tehran, Islamic Republic of Iran

F L Munier, Ocular Genetics Unit, Hôpital Jules Gonin, Lausanne, Switzerland

${ }^{*} \mathrm{C}$ E Willoughby and Sara Arab contributed equally to the project.

Correspondence to: Dr E Héon, Department of Ophthalmology, The Hospital for Sick Children, 555 University Avenue, Toronto, Ontario M5G 1X8, Canada; eheon@attglobalnet.com

\section{REFERENCES}

1 World Health Organisation. The World Health report: life in the $21 \mathrm{st}$ century-a vision for all. Geneva: WHO, 1998:47.

2 Taylor HR. Cataract: how much surgery do we have to do? Br J Ophthalmol 2000;84: 1-2.

3 Lewallen $S$, Courtright P. Blindness in Africa: present situation and future needs. Br J Ophthalmol 2001:85:897-903.

4 Francis PJ, Berry V, Bhattacharya SS, et al. The genetics of childhood cataract. J Med Genet 2000;37:481-8.
5 The Framingham Offspring Eye Study Group. Familial aggregation of lens opacities: the Framingham Eye Study and the Framingham Offspring Eye Study. Am J Epidemiol 1994; 140:555-64.

6 Francois J. Genetics of cataract. Ophthalmologica 1982;184:61-71.

7 lonides A, Francis $\mathrm{P}$, Berry V, et al. Clinical and genetic heterogeneity in autosomal dominant congenital cataracts. Br J Ophthalmol 1999;83:802-8.

8 Hammond CJ, Snieder H, Spector TD, et al. Genetic and environmental factors in age-related nuclear cataracts in monozygotic and dizygotic twins. N Engl $J$ Med 2000;342:1786-90

9 Hammond CJ, Duncan DD, Snieder $\mathrm{H}$, et al. The heritability of age-related cortical cataract: the Twin Eye Study. Invest Ophthalmol Vis Sci 2001;42:601-5.

10 Shiels A, Mackay D, lonides A, et al. A missense mutation in the human connexin 50 gene (GJA8) underlies autosomal dominant "zonular pulverulent" cataract, on chromosome 1q. Am J Hum Genet pulverulent cataract

11 Berry V, Mackay D, Khaliq S, et al. Connexin 50 mutation in a family with congenital "zonular nuclear" pulverulent cataract of Pakistani origin. Hum Genet 1999;105:168-70.

12 Polyakov AV, Shagina IA, Khlebnikova OV, et al. Mutation in the connexin 50 gene (GJA8) in a Russian family with zonular pulverulent cataract. Clin Genet 2001;60:476-8.

13 Tusnady GE, Simon I. The HMMTOP transmembrane topology prediction server. Bioinformatics 2001;17:849-50.

14 Chang B, Wang X, Hawes NL, et al. A Gja8 (Cx50) point mutation in semidominant cataracts of Lop10 mice. Hum Mol Genet 2002;1 1:507-13.

15 Simon AM, Goodenough DA. Diverse functions of vertebrate gap junctions. Trends Cell Biol 1998:8:477-83.

16 Bruzzone R, White TW, Paul DL. Connections with connexins - the molecular basis of direct intercellular signalling. Eur J Biochem 1996;238:1-27.

17 Sipos L, von Heijne G. Predicting the topology of eukaryotic membrane proteins. Eur J Biochem 1993;213:1333-40.

18 Verselis VK, Ginter CS, Bargiello TA. Opposite voltage gating polarities of two related connexins. Nature 1994;368:348-51.

19 Purnick PE, Benjamin DC, Verselis VK, et al. Structure of the amino terminus of a gap junction protein. Arch Biochem Biophys 2000;381:181-90.

20 Rouan F, White TW, Brown N, et al. Trans-dominant inhibition of connexin43 by mutant connexin-26: implications for dominant connexin disorders affecting epidermal differentiation. J Cell Sci 2001;114:2105-13.

21 Ressot C, Latour P, Blanquet-Grossard F, et al. X-linked Charcot-Marie-Tooth neuropathy (CMTX): new mutations in the connexin 32 gene. Hum Genet 1996:98:172-5.

22 Kelsell DP, Di WL, Houseman MJ. Connexin mutations in skin disease and hearing loss. Am J Hum Genet 2001;68:559-68.

23 Krutovskikh V, Yamasaki H. Connexin gene mutations in human genetic diseases. Mutat Res 2000:462:197-207.

24 Richard G, Rouan F, Willoughby CE, et al. Missense mutations in the GJB2 encoding connexin-26 cause the ectodermal dysplasia keratitis-ichthyosisdeafness syndrome. Am J Hum Genet 2002;70:1341-8.

25 Beyer EC, Paul DL, Goodenough DA. Connexin a protein from rat heart homologous to a gap junction protein from liver. $J$ Cell Biol 1987; 105:2621-9.

26 Paul DL, Ebihara L, Takemoto, et al. Connexin 46, a novel lens gap junction protein, induces voltage-gated currents in nonjunctional plasma membrane of Xenopus oocytes. J Cell Biol 1991;115:1077-89.

27 White TW Bruzzone R, Goodenough DA, et al. Mouse Cx50, a functiona member of the connexin family of gap junction proteins, is the lens fiber protein MP70. Mol Biol Cell 1992;3:711-20.

28 Goodenough DA. The crystalline lens. A system networked by gap junctional intercellular communication. Semin Cell Biol 1992;3:49-58.

29 White TW. Unique and redundant connexin contributions to lens development. Science 2002;295:319-20.

30 Xu X, Ebihara L. Characterization of a mouse Cx50 mutation associated with the No2 mouse cataract. Invest Ophthalmol Vis Sci, 1999:40:1844-50.

31 Steele EC, Lyon MF, Favor J, et al. A mutation in the connexin 50 (Cx50) gene is a candidate for the No2 mouse cataract. Curr Eye Res 1998; 17:883-9.

32 Rong P, Wang X, Niesman I, et al. Disruption of Gja8 ( $\alpha 8$ connexin) in mice leads to microphthalmia associated with retardation of lens growth and lens fiber maturation. Development 2002;129:167-74.

33 White TW, Goodenough DA, Paul DL. Targeted ablation of connexin 50 in mice resulting in microphthalmia and zonular pulverulent cataracts. J Cell Biol 1998; 143:815-25.

34 Mackay D, lonides A, Kibar Z, et al. Connexin 46 mutations in autosomal dominant congenital cataract. Am J Hum Genet 1999:64:1357-64.

35 Gong X, Li E, Klier G, et al. Disruption of $\alpha 3$ connexin gene leads to proteolysis and cataractogenesis in mice. Cell 1997;91:833-43.

36 Runge PE, Hawes NL, Heckenlively JR, et al. Autosomal dominant mouse cataract (Lop10). Invest Ophthalmol Vis Sci 1992;33:3203-8.

37 Gill D, Klose R, Munier FL, et al. Genetic heterogeneity of the Coppock-like cataract: a mutation in CRYBB2 on chromosome 22q1 1.2. Invest Ophthalmol Vis Sci 2000;41:159-65.

38 Thompson JD, Gibson TJ, Plewniak F, et al. The ClustalX windows interface: flexible strategies for multiple sequence alignment aided by quality analysis tools. Nucleic Acids Res 1997:24:4876-82. 